\title{
Abracadabra, the relation between stress and rhythm
}

\section{Anneke Neijt}

\section{Introduction ${ }^{1}$}

Generative linguistic theory aims to characterize what human beings know about their language, the structure they assign to utterances. Research over the past thirty years has shown that the structural complexities of language are understood best in a modular approach, with components or levels of description with autonomous internal consistency, and a mapping relation between these. For instance: separate constituent structures in prosodic phonology and syntax, separate tiers in segmental phonology for the description of manner and place of articulation.

This paper addresses stress and rhythm, two levels within prosodic phonology. The first section shows the necessity to distinguish between both levels. The sections thereafter show that the position of main stress is dependent on rhythm and that rhythm is dependent on the position of main stress, in a way that seems to require global rules or constraints. Stress and rhythm thus illustrate the challenge of future linguistics: to explain how different levels of language structure are related to one another.

\section{The distinction between stress and rhythm}

Stress and rhythm are not the same. Stress is assigned to words and phrases in order to establish heads and dependents. Rhythm forms chunks of information with an iterative pattern. Consider for instance single digit pronunciation of telephone numbers, with groups of two or three syllables, according to rhythmic constraints that hold for poetry as well. The number 0243612048 will be split in $024-36-120-48$, or $02-43-61-20-48$, or any other pattern of two or three syllables, as illustrated in (1).

$$
\begin{aligned}
& \text { Rhythmic structure of strings of numbers } \\
& \text { 024-36-120-48 } \cup \cup-/ \cup-/ \cup \cup-/ \cup- \\
& \text { 02-43-61-20-48 } \cup-/ \cup-/ \cup-/ \cup-/ \cup-
\end{aligned}
$$

\footnotetext{
${ }^{1}$ My thanks go to Mirjam Ernestus, Paula Fikkert and Judith Hanssen for their comments. All disclaimers apply.
} 
Such constituents of two or three elements are rhythmic feet, for which a notation with macrons $(-)$ for beat positions and breves $(\cup)$ for lapses between the beats is current in poetic analyses. Strings of feet form perfect rhythms when (a) a pattern of at least two beats is created, (b) beat positions are not adjacent, and (c) no more than two lapses occur between the beats.

One of the essential differences between rhythm and stress is structural depth. For rhythm a constituent structure with most often only two layers of information is needed: the items relevant for rhythm (in our examples: syllables) and the prominence relations between these. In exceptional cases, rhythmic patterns are embedded in larger rhythmic patterns, as in the phrasing 0243-61-2048, with phrases of four syllables that consist of the smaller phrases $02-43$ and 20-48. Stress structures on the other hand contain constituents that in principle are as deeply embedded as syntactic constituents, although of course they are subdivided into flatter structures in phonology.

Another difference between stress and rhythm manifests itself in focus assignment. Stress, but not rhythm, determines the scope of accents. For instance, contrastive accent on the modifier of a compound in Dutch will allow for both wide and narrow scope, whereas contrastive accent on the head of a compound signals narrow scope only, cf. (2). In these examples, the syllable with main stress is underlined, and capitalization indicates the syllable with contrastive accent.

(2) a. TIMmerman of kapiTEIN 'carpenter or captain'

(wide scope: CARPENTER contrasts with CAPTAIN)

b. TIMmerman of KLUSjesman 'carpenter or handyman'

(wide or narrow scope: TIMMER 'to hammer' contrasts with KLUSJES 'odd jobs')

c. TímmerMAN of timmerVROUW 'carpenter or carpentry-woman' (narrow scope only: MAN 'man' contrasts with VROUW 'woman')

The relation between contrastive accent and stress is systematic and functional: wide scope interpretations are available only for domains in which main stress and accent coincide. When main stress is overruled by constrastive accent, only the narrow scope interpretation is available. This is illustrated by (2c), in which the accented syllable is more prominent than the syllable with main stress in the compound. 
Mismatches between accent and rhythm, on the other hand, are irrelevant. Syllables with contrastive accent often are rhythmically prominent as well, but they need not be so, cf. (3).

(3) a. Ōp eěn NIĚT pāssěnd mŏmēnt willlěn kōměn.

b. Ât ă NǑT suītăblě mōměnt, thěy wānt tŏ ărīive.

In (3), syllables with main word stress are underlined, syllables indicating contrastive accents are capitalized and rhythm is indicated with macrons and breves. The examples in (3) show that scope of focus is independent of rhythm, those in (2) show that scope of focus depends on stress. Mismatches of stress and accent are informative, but mismatches of rhythm and accent are not.

Another indication of the difference between stress and rhythm is variation. Within a focus domain, the position of main stress is fixed, but rhythm is variable. Consider for instance the names Ithaka and Polyfeides. When pronounced in isolation, full rhythm is required (Ithăk $\bar{a}$ and Pŏly̆feìděs), a pattern with at least two beat positions, ( $\cup \cup$ and $-\cup-$ $\cup$ ). When embedded in an utterence, a reduced rhythmic form, with only one beat, is available. Compare (4a) and (4b), from lines of hexameters, a context that requires iterations of six feet, $-\cup \cup$ or $-\cup$ (Homerus Odyssee, ed. De Roy van Zuydewijn, 1992).

(4) a. Full rhythm

ōvěr tě hālěn zujjn Îthăkā tě věrgētěn

'to persuade to forget his Ithaka'

... maāktě Apōllŏ/

Pōly`feīděs tōt dě uǐtnēměndstě ziēněr dĕr mēnsěn (Book xv:258)

'Apollo made Polyfeides the best visionary of mankind'

b. Reduced rhythm

Zēlf zăl îk nū naăr İthăkă gaān ŏm zijjn zoōn tě běziēlěn (Book i:90)

'I myself wil go now to Ithaka to inspire his son'

zō oŏk Māntǐŏs, dīe Pŏly̆feīděs vĕrwēktě ěn Kleītŏs (Book xv:252)

'so too Mantios, who begot Polyfeides and Kleitos'

Finally, rhythmic variation is not only dependent on context, but also on tempo, as illustrated by the magic word ābrăcădā bră, in slow speech pronounced as $\bar{a} b r \bar{a} c a ̆ d \underline{a} b r \bar{a}$. The rhythmic realization is variable, though the position of main stress remains unchanged. In sum, structural depth, 
focus and variation show that stress and rhythm need different levels of description.

\section{Rhythm's influence on the position of main stress}

Even though there are good reasons to assume that stress and rhythm require different levels of description, there is a tight connection between the two, as is evident for instance in studies on the typology of stress systems and in studies on stress clashes. Interestingly, we also found influences of stress clash on the position of main stress in simplex words (Ernestus and Neijt to appear). The conclusions of our paper are that the location of main stress in Dutch, German, and English monomorphemic words is affected by word length and that there is important variation. In the context of the present paper it will be relevant to consider in more detail how the number of syllables in the word (three or four) may affect the position of main stress, because it will be shown that rhythm codetermines the position of main stress.

In our study, we collected judgements by native speakers on the position of main stress in pseudowords. The words varied in their number of syllables (three or four), but the final three syllables were identical. The weight of these syllables allows the position of main stress to vary, see (5).

(5) Phonological restrictions of the words included in the experiments

a. final syllables are

(i) closed (VC) or open (VV) in Dutch and German,

(ii) and heavy (VVC or VCC) or light (VC) in English

b. prefinal syllables are open (VV) in all three languages

Several lists of pseudowords were created, such that participants saw either the quadrisyllabic or the trisyllabic version of a word. For instance, one list contained potabovoo and bokatass, another list contained tabovoo and dibokatass. This way, the factor length formed the only variable factor, under the assumption that stress is assigned from right to left in Dutch, German, and English. Chart (6a) presents the distribution of penultimate stress assignments. Interestingly, chart (6b) shows that the variation in preferences for main stress by native speakers observed in the pseudoword experiment is also present grosso modo in the CELEX-corpora, which contain 311 Dutch, 55 German and 116 English simplex words of three and four syllables with the characteristics of (5). 
(6) a. Penultimate main stress in pseudoword experiments $(\%, n=2343)$

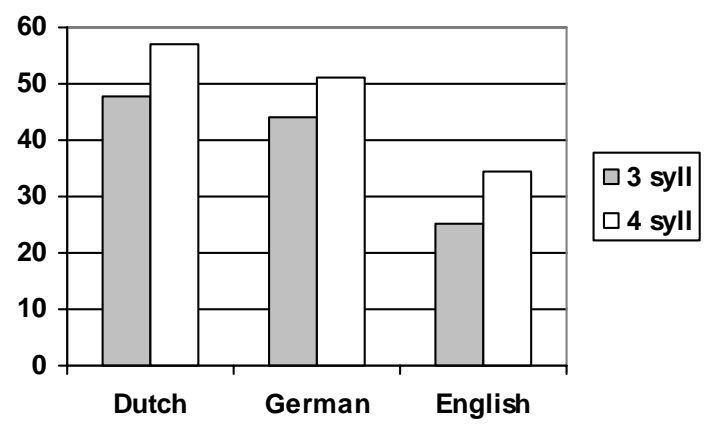

b. Penultimate main stress in existing words $(\%, n=146)$

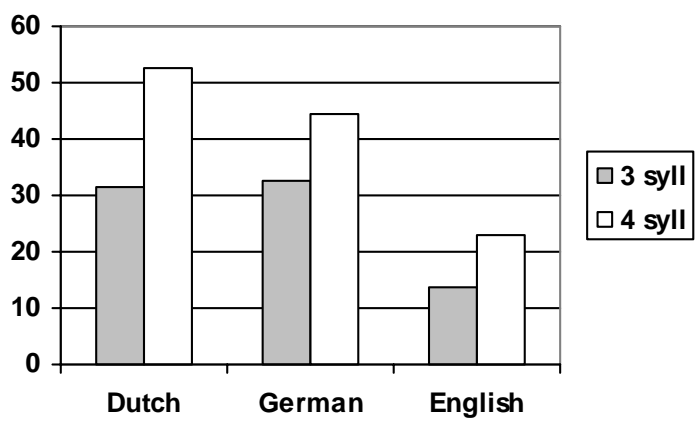

The differences between the languages, which may be due to other factors such as differences in syllable weight, are of no concern to the issue at hand. For the purposes of our investigation, the similarities between the languages are important. In each language, penultimate stress is assigned more often in words of four syllables than in words of three syllables. Similar, but mirror imaged charts represent the distribution of antepenultimate and final stress in words of three or four syllables. The preferences found are:

(7) a. Antepenultimate stress:

more often assigned to words of three syllables.

b. Penultimate stress:

more often assigned to words of four syllables.

c. Final stress:

more often assigned to words of three syllables. 
We explain this effect of length as being driven by a preference for initial stressed syllables and alternating patterns of stressed and unstressed syllables. The following tableau illustrates the relation between stress and full rhythm (notice that the pseudoword experiment evoked full rhythm, because the words were presented in isolation, as items of a list).

(8)

\begin{tabular}{|c|c|c|c|}
\hline & ANTEPENULTIMATE & PENULTIMATE & FINAL STRESS \\
\hline 3 syllables & $\underline{\underline{a}} \mathbf{r i a}$ & $\begin{array}{l}\text { Maria } \\
\cup=\cup\end{array}$ & $\begin{array}{l}\text { chocola } \\
-\cup=\end{array}$ \\
\hline 4 syllables & $\begin{array}{l}\text { Penelope } \\
\cup \simeq \cup-\end{array}$ & $\begin{array}{l}\text { rododendron } \\
-\cup-\cup\end{array}$ & $\begin{array}{l}\text { filatelie } \\
\cup-\cup-\text { or } \\
-\cup \cup-\end{array}$ \\
\hline
\end{tabular}

On the basis of general constraints on perfect rhythm (at least two beats, no clashes or lapses), and the assumption that rhythm signals initial word edges in Germanic languages, the explanation of the patterns found are as follows (comparing rhythm in the columns of this tableau, according to the design of our experiment):

(9) antepenultimate stress: $-\cup-$ is preferred over $\cup-\cup-$ penultimate stress: $-\cup-\cup$ is preferred over $\cup-\cup$ final stress:

$$
-\cup-\text { is preferred over } \cup-\cup-\text { (but equals }-\cup \cup-\text { ). }
$$

Alternatively, one might compare the set of rhythms available for words of three or four syllables (the rows in the tableau):

(10) 3 syllables: $-\cup-$ is preferred over $\cup-\cup$, and 4 syllables: $-\cup-\cup$ and $-\cup \cup-$ are preferred over $\cup-\cup-$.

Both ways, rhythm straightforwardly explains the length pattern found in the three languages.

\section{Stress's influence on rhythm}

The variation in rhythmic phrasing is influenced by context. Reconsider the poetic lines in (4), which show that preceding and following context determine rhythmic phrasing of variable words such as Ithaka and 
Polyfeides. The following pilot experiment shows that this context effect can be observed within words as well: the position of main stress at the end of the word codetermines rhythmic phrasing of the initial part of the word.

Thirty six participants, speakers of Dutch, were asked to determine phrasing within a word, as they would do, for instance, in explicit diction of the word ondoorgrondelijk 'incomprehensible': on/doorgron/delijk, or ondoor/gronde/lijk, or any other partition. The data presented (mostly unknown words or pseudowords with an odd number of syllables before the position of main stress; this position underlined and bold) and the results are summarized in (11). Sometimes participants divided a word into monosyllabic groups only (cf. on/door/gron/de/lijk). Such answers are uninformative and therefore not included in (11). The word abracadabra was incorporated with its three reduction variants (schwa written in this experiment as $e$, the usual orthographic form of schwa in Dutch).

(11) Rhythmic phrasing at word onset

After each word, the number of answers with a first constituent of respectively one, two, three, four or even five syllables is presented, along with the distribution of initial constituents with one, two and three syllables in percentages.

a. Antepenultimate stress: amorosissimo $10-12-12-1-0$ (29-35-35\%) mimimimimimimimi 3-13-14-2-2 (10-43-47\%)

b. Penultimate stress: abracadabra 7-29-0-0-0; abracedabra 11-22-3-0-0; abrecadábra 4-29-3-0-0; abrecedäbra 7-18-11-0-0 (20-68-12\%) amerikanisme 17-8-3-8-0 (61-29-11\%) latitudinarisme 8-21-5-1-0 (24-62-15\% dudududududúdu 3-18-10-1-2 (11-57-32\%)

c. Final stress:

$$
\begin{aligned}
& \text { fonologie } 5-27-3-0-0(9-81-9 \%) \\
& \text { tatatatatata } 0-18-12-1-2(0-59-41 \%)
\end{aligned}
$$

The data collected for amerikanisme 'americanism' suggest that not only length of the word determines the choices, but also morphology. The fact that the base of this complex word, amerika, has four syllables undoubtedly influenced the high number ( 8 choices) of first constituents with four syllables in this word. The issue of the influence of morphology on rhythmic phrasing needs further study. 
Several trends can be observed. First, in longer words, participants prefer larger phrases. Observe that larger constituents are also prefered in the reduced forms of abracadabra, illustrating the relation between syllable weight, speech tempo, and seize of rhythmic constituents. Second, in words with final and penultimate stress, initial constituents of two syllables are most frequent (with the exception of amerikanisme, cf. above). This suggests that rhythmic phrasing is applied from left to right (which forms further evidence for the suggestion by Ernestus and Neijt, and others, that prosody indicates word onsets in Germanic languages). Third, and most important for the issue of this paper, the position of main stress influences rhythm. The highest mean percentage of trisyllabic first constituents is found in words with antepenultimate stress. Rhythmic phrasing at the end of the word, induced by the position of main stress, influences rhythmic phrasing of word onset.

\section{Conclusion}

The miraculous abracadabra of human language, its robustness and flexibility, is due to its multitude of levels, and the intricate ways these levels relate. Above data illustrate the issue of matching and mismatching levels in a nutshell. Using familiar terminology of generative grammar, the influence of rhythm on the position of main stress can be characterized as a global mechanism in which different derivations are evaluated. Similarly, the influence of the position of main stress on rhythmic phrasing can be characterized as a mechanism in which several options of phrasing the string are evaluated, and most often the best option is chosen. It turns out that the individual rules, constraints, or patterns within a level are strictly local, but preferences of use and interpretation are governed by comparison of different levels of the same derivation or of different derivations. Even though derivations are no longer part and parcel of current linguistic approaches, the concepts introduced will be useful in new frameworks, and it still makes sense to aim at local descriptions, to distinguish types of globality, and to further investigate the relation between levels.

\section{References}

Ernestus and Neijt. To appear. Word length and the location of primary word stress in Dutch, German, and English. Linguistics. 